\title{
A Study on the Influencing Factors of Medical Students' Behavior of Seeking Medical Treatment and the Utilization of Medical Service
}

\author{
Qian $\mathrm{Yu}^{1}$, Xiaoxiang Zhang ${ }^{1}$, \\ ${ }^{1}$ School of Management of Hubei University of Chinese Medicine, Wuhan City, Hubei Province, China
}

\begin{abstract}
By using questionnaire survey and statistical analysis method, this paper studies the influencing factors of medical students' behavior of seeking medical care and the utilization of medical services. It is found that there are three main choices of medical students' behavior of seeking medical care after illness, which are school hospital, community health service center and self-treatment, accounting for $36.5 \%, 24.2 \%$ and $15.9 \%$ respectively. And the grade, place of origin, medical security system and self-rated health status had significant effects on medical students' medical behavior $(\mathrm{P}<0.05)$. The place of origin and medical security system were the main influencing factors of medical students' utilization of medical services $(\mathrm{P}<0.05)$.Therefore, in order to guide the medical students to go to a doctor correctly and promote the effective use of medical services, the first is to enhance the medical care consciousness of medical students, the second is to develop the health management of college students, the third is to improve the medical service ability of school hospitals, the fourth is to perfect the medical security system of college students.
\end{abstract}

\section{Introduction}

As the main force of the future medical service industry, the health of medical students plays an important role in the development of national medical and health undertakings. Through the investigation of 1027 medical students in nine universities in the United States, $\mathrm{Wu}$ Minmin ${ }^{[1]}$ concluded that the behavior of medical students in seeking medical treatment will affect their attitude towards patients in the future. Therefore, it can be seen that Medical students' behavior of seeking Medical treatment will affect the future development of doctor-patient relationship to some extent, but there are few data to study medical students' behavior of seeking Medical treatment at present

This paper describes the medical needs, medical service utilization and medical security status of medical students by means of questionnaire survey, and then analyzes the influencing factors of medical students' medical treatment behavior and medical service utilization by means of test and multiple Logistic regression, and on this basis, provides suggestions for guiding medical students to seek medical treatment correctly and promoting the effective utilization of medical services.

\section{Data and Methods}

\subsection{Survey Subjects and Sampling Methods}

\footnotetext{
* Corresponding author: 422616556@qq.com
}

The subjects of this study were full-time undergraduate and graduate students of Hubei University of Chinese Medicine (excluding overseas students from Hong Kong, Macao and Taiwan). The dormitory floors were selected by stratified sampling method, and the dormitories were selected by isometric sampling method. The investigator $\mathrm{s}$ randomly selected two students from the dormitory me mbers to complete the field questionnaire distributing, filling in and collecting.

\subsection{Quality Control}

Properly arrange the investigation methods and procedures before the investigation, unify the training and assessment of investigators; In the survey, the interviewees completed the questionnaire alone, and the questionnaire was collected on the spot after being carefully checked by the investigators; the data entry of the questionnaire after the investigation follows the principle of double blindness.

\subsection{Statistical Treatment}

The questionnaire data were statistically analyzed by SPSS 10.0 statistical software, and the influencing factors of medical students' medical treatment behavior and medical service utilization were analyzed by means of test and multiple Logistic regression. 


\section{Description of Research Results}

\subsection{Sample Description}

A total of 390 questionnaires were sent out, 366 valid questionnaires were received, and the effective recovery rate was $93.8 \%$.

Among them, there were 199 medical students, accounting for $54.37 \%$, and the basic information of the sample students was shown in Table 1.

Table 1. Basic Information of Sample Students

\begin{tabular}{|c|c|c|c|}
\hline \multicolumn{2}{|c|}{ Variable } & \multirow{2}{*}{$\begin{array}{c}\text { Medical } \\
\text { students }\end{array}$} & \multirow{2}{*}{$\begin{array}{c}\begin{array}{c}\text { Non-medical } \\
\text { students }\end{array} \\
51\end{array}$} \\
\hline \multirow{2}{*}{ Gender } & Male & & \\
\hline & Female & 140 & 121 \\
\hline \multirow{2}{*}{$\begin{array}{c}\text { Place of } \\
\text { origin }\end{array}$} & Town & 101 & 80 \\
\hline & Country & 90 & 91 \\
\hline \multirow{6}{*}{ Grade } & Freshman & 65 & 54 \\
\hline & Sophomore & 82 & 64 \\
\hline & Junior & 33 & 45 \\
\hline & Senior & 17 & 13 \\
\hline & $\begin{array}{c}\text { fifth year } \\
\text { undergraduate }\end{array}$ & 1 & 0 \\
\hline & Postgraduate & 3 & 2 \\
\hline \multirow{5}{*}{$\begin{array}{c}\text { Self-rated } \\
\text { Health } \\
\text { Status }\end{array}$} & Very poor & 2 & 0 \\
\hline & poor & 42 & 31 \\
\hline & general & 81 & 80 \\
\hline & good & 61 & 48 \\
\hline & Very good & 5 & 12 \\
\hline \multirow{2}{*}{$\begin{array}{l}\text { Medical } \\
\text { Security }\end{array}$} & Insured & 131 & 101 \\
\hline & Uninsured & 60 & 70 \\
\hline
\end{tabular}

\subsection{Description of Current Medical Needs}

Table 2. Behavior Selection for Medical Treatment

\begin{tabular}{|c|c|c|c|c|}
\hline \multirow{2}{*}{} & \multicolumn{2}{|c|}{$\begin{array}{c}\text { Medical } \\
\text { students }\end{array}$} & \multicolumn{2}{c|}{$\begin{array}{c}\text { Non-medical } \\
\text { students }\end{array}$} \\
\cline { 2 - 5 } & Male & Female & Male & Female \\
\hline $\begin{array}{c}\text { University } \\
\text { Hospital }\end{array}$ & 20 & 49 & 23 & 39 \\
\hline $\begin{array}{c}\text { Community } \\
\text { Health Center }\end{array}$ & 10 & 35 & 9 & 39 \\
\hline Private Clinic & 1 & 7 & 1 & 4 \\
\hline 3a Hospital & 5 & 14 & 3 & 12 \\
\hline Other hospitals & 4 & 8 & 4 & 5 \\
\hline
\end{tabular}

\begin{tabular}{|c|c|c|c|c|}
\hline Self-treatment & 8 & 22 & 14 & 17 \\
\hline Indifferent & 1 & 5 & 4 & 3 \\
\hline
\end{tabular}

According to Table 2, the rates of male and female patients seeking medical treatment were $74.77 \%$ and $81.85 \%$, respectively, which showed that female students have higher demand for medical services than male students. The rates of medical students and non-medical students were $80.95 \%$ and $78.53 \%$ respectively, indicating that the medical needs of medical students were slightly higher than those of non-medical students.

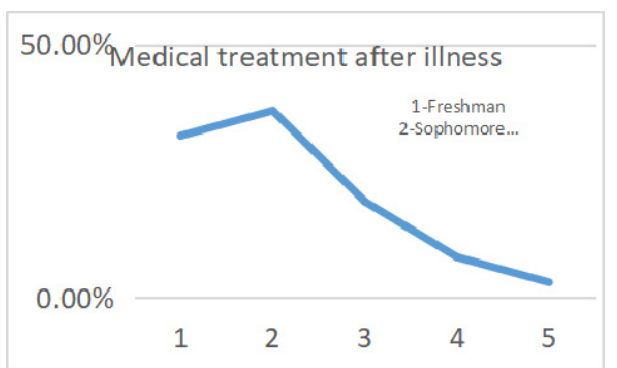

Fig. 1. Medical Treatment Rate and Grade Distribution

From figure 1, it can be seen that the rate of medical treatment of medical students increased at first and then decreased, and the rate reached the peak in the second year of undergraduate study, that is to say, the demand for medical service of senior medical students was less than that of junior medical students.And the rate of medical treatment of college students from rural areas is $45.2 \%$, which is about 10 percentage points higher than that of college students from urban areas. It can be seen that college students from rural areas have higher demand for medical services than those from urban areas.

\subsection{Description of Medical Service Utilization}

According to Table 2,the utilization rate of medical services reached $80.95 \%$, and there were three main medical treatment behaviors of medical students after illness, which were school hospital, community health service center and self-treatment, accounting for $36.5 \%$, $24.2 \%$ and $15.9 \%$ respectively. The results of this survey show that $6 \%$ of the sample college students felt that their health status was very poor, of which the hospitalization accounts for $1.6 \%$. It can be inferred that the use of medical services by medical students is mainly concentrated in the outpatient department. This prediction can be verified by the data in Table 3, that is, $95.90 \%$ of the sample college students sought medical services in the outpatient department after illness.

Table 3. Types of Medical Services Sought by College Students after Illness

\begin{tabular}{|c|c|c|}
\hline Type & Frequency & Percentage $(\%)$ \\
\hline Outpatient & 351 & 95.90 \\
\hline In-patient & 6 & 1.64 \\
\hline Emergency & 4 & 1.09 \\
\hline Other & 5 & 1.37 \\
\hline
\end{tabular}




\subsection{Description of Medical Security}

Table 4. Insured by Different Majors and Grades

\begin{tabular}{|c|c|c|c|c|}
\hline \multirow{2}{*}{} & \multicolumn{2}{|c|}{ Medical students } & \multicolumn{2}{c|}{$\begin{array}{c}\text { Non-medical } \\
\text { students }\end{array}$} \\
\cline { 2 - 5 } & Insured & Uninsured & Insured & Uninsured \\
\hline Freshman & 52 & 10 & 45 & 11 \\
\hline Sophomore & 42 & 32 & 24 & 38 \\
\hline Junior & 26 & 7 & 19 & 22 \\
\hline Senior & 10 & 4 & 7 & 5 \\
\hline $\begin{array}{c}\text { fifth year } \\
\text { undergraduate }\end{array}$ & 0 & 1 & 0 & 0 \\
\hline Postgraduate & 3 & 1 & 1 & 1 \\
\hline
\end{tabular}

According to Table 4, 36.94\% of the sample medical students have purchased medical insurance for college students, which was about 10 percentage points higher than that of non-medical students, indicating that medical students have relatively high awareness of medical security. However, $36.38 \%$ of the sample college students did not participate in the medical insurance in general, and the Medical students accounted for about $28.49 \%$. There were three main reasons why medical students do not participate in basic medical insurance, which were good health, other insured medical insurance and the poor medical service level, accounting for $15.30 \%, 14.75 \%$ and $14.21 \%$, respectively.

\section{Analysis of Research Results}

\subsection{Analysis of the Causes of Illness without Seeking Medical Treatment}

Through this study, it is found that $19.05 \%$ of the sample medical students did not seek medical treatment after illn ess. By analyzing the survey results of indirect questions the specific reasons can be obtained as follows.

\subsubsection{Economic Hardship}

Some studies have shown that economic factors are important barriers to the inability of individuals to make successful use of medical services after illness. There are two reasons for this phenomenon, one is the financial difficulties of the family.For this part of the population, in the event of illness ${ }^{[2]}$, the financial pressure on their families is very great.Second, medical expenses are growing too fast relative to residents' income. The study shows that since 2000 , the average annual outpatient cost has increased by $13 \%$, and the hospitalization cost has increased by $11 \%$, all of which exceed the increase in residents' income.

\subsubsection{Self-treatment}

There are $16.67 \%$ of the sample college students choose self-treatment after illness who choose self-treatment after illness, which is mainly due to the improvement of people's health awareness and the development of Internet technology, so it is more convenient for us to obtain medical and health knowledge. In addition, college students, as a group of young adults, have good physical quality, low prevalence and mild symptoms. At the same time, because of certain medical knowledge and clinical experience, medical students are more likely to adopt the way of self-treatment when they have uncomfortable symptoms.

\subsubsection{No Need for Medical Treatment}

Nowadays, college students are generally faced with the pressure of textual research, postgraduate entrance examination and employment. It is very common for them to choose not to seek medical treatment if the illness is not too serious. This phenomenon is mainly due to the students themselves conscious symptoms are not too serious, through rest, adjustment of diet and other ways can be cured; Secondly, the opportunity cost of medical treatment is relatively high.

\subsection{Analysis on the Influencing Factors of Medical Students' Behavior of Seeking Medical Treatment}

\subsubsection{Gender}

From Table 8, it can be seen that gender has no significant effect on medical students' behavior of seeking medical treatment $(\mathrm{P}>0.05)$. The influence of gender factors on the behavior of seeking medical treatment has not reached the same conclusion among different studies. Some studies have shown that, from a psychological and physiological perspective, girls are more active in seeking medical treatment than boys ${ }^{[1]}$. However, other studies have shown that there is no statistical significance in the post-treatment methods of male and female college students with physical conditions $^{[3]}$, and the results of this survey are consistent with the latter studies.

\subsubsection{Grade}

The results showed that medical students of different grades had different behavior in seeking medical treatment and the difference was statistically significant $(\mathrm{P}<0.05)$. This the fact may be that medical students have just left their family life two years before entering the school, and are relatively dependent on the school and tend to go to the school hospital for medical treatment after illness. However, in the later stage, due to the arrangement of curriculum and extra-curricular activities, medical students have less disposable time, and with the deepening of medical education, they have more medical knowledge. Therefore, when disease risks occur, medical students may choose to leave them alone or adopt the way of self-treatment. 


\subsubsection{Place of Origin}

The place of origin had a significant influence on the behavior of medical students seeking medical treatment $(\mathrm{P}<0.05)$, and the college students from urban areas were more inclined to seek medical treatment after illness than those from rural areas. This conclusion is consistent with the reality, and the fundamental reason lies in the difference of economic income between urban and rural families. Generally speaking, the economic status of urban families is better than that of rural families, and a better family income status can enable students to transform their needs for medical services into effective demands after they get sick.

\subsubsection{Personal Living Expenses}

There was no significant effect of personal living expenses on medical students' behavior of seeking medical treatment $(\mathrm{P}>0.05)$. For medical students who have no source of income,the cost of medical care caused by illness is flexible as an additional living expense. Therefore, for medical students with mild conscious symptoms after illness, in order to reduce the living expenses, they will tend not to seek medical treatment or take the form of self-treatment.

\subsubsection{Medical Security}

Whether or not to buy medical insurance for college students had a significant effect on medical students' behavior of seeking medical treatment $(\mathrm{P}<0.05)$. The relevant data show that the proportion of general outpatient reimbursement for college students is no less than $70 \%$. Compared with $50 \%$ of the general outpatient reimbursement ratio of residents' medical insurance, students who buy college students' medical insurance enjoy better medical treatment. Therefore, the purchase of medical insurance for college students has a positive impact on the behavior of medical students to seek medical treatment.

\subsubsection{Self-rated Health Status}

The self-rated health status had a significant impact on medical students' behavior of seeking medical treatment $(\mathrm{P}<0.05)$, and the direction of the impact was consistent with the expectation, that is, compared with college students with good Self-assessment health status, college students with poor self-assessment health status were more inclined to take positive medical treatment behavior, which was also confirmed in Yu Dachuan's $\operatorname{research}^{[4]}$.

Table 5. the Influencing Factors of Medical Students' Behavior of Seeking Medical Treatment

\begin{tabular}{|c|c|c|}
\hline Variable & $\chi^{2}$ & $\mathrm{P}$ \\
\hline Gender & 4.408 & 0.718 \\
\hline Grade & 18.166 & 0.011 \\
\hline Place of Origin & 20.708 & 0.004 \\
\hline
\end{tabular}

\begin{tabular}{|c|c|c|}
\hline Personal Living Expenses & 10.343 & 0.170 \\
\hline Medical Security & 17.672 & 0.014 \\
\hline Self-rated Health Status & 35.644 & 0.000 \\
\hline
\end{tabular}

\subsection{Analysis on the Influencing Factors of Medical Service Utilization}

From the above analysis, it can be concluded that grade, place of origin, whether to buy medical insurance for college students and self-assessment of health status have a significant impact on the medical students' behavior of seeking medical treatment. On this basis, through multiple Logistic regression analysis, it was found that the place of origin and the purchase of medical insurance were the significant factors affecting the utilization of medical services for medical students. (See Table 9 for details)

Table 6. the Impact of Medical Service Utilization

\begin{tabular}{|c|c|c|c|c|}
\hline Variable & $\begin{array}{c}\text { Regression } \\
\text { Coefficient }\end{array}$ & $\begin{array}{c}\text { Standard } \\
\text { Error }\end{array}$ & $\begin{array}{c}\text { Wald } \\
\chi^{2}\end{array}$ & $\mathrm{P}$ \\
\hline $\begin{array}{c}\text { Place of } \\
\text { Origin }\end{array}$ & 1.714 & 0.336 & 25.992 & 0.000 \\
\hline $\begin{array}{c}\text { Medical } \\
\text { Security }\end{array}$ & 1.051 & 0.367 & 8.201 & 0.004 \\
\hline Constant & -21.334 & 1.100 & 0.031 & 0.996 \\
\hline
\end{tabular}

\section{Conclusions}

\subsection{The Behavior of Medical Students who do not Seek Medical Treatment is Worth Paying Attention to.}

This study shows that $19.05 \%$ of the sample medical students did not seek medical treatment after falling ill.In view of this group,we should pay attention to and take measures to transform their needs for medical services into actual needs, so as to promote the effective use of medical services and the healthy development of medical students.

\subsection{Medical Students' Behavior of Seeking Medical Treatment is Affected by Many Factors.}

Through this study, it can be concluded that grade, place of origin, whether to buy medical insurance for college students, and self-assessment of health status have significant effects on medical students' behavior of seeking medical care, among which place of origin and medical security system are the main influencing factors of medical service utilization.

\section{Suggestions}

\subsection{Enhance Medical Care Consciousness}

Firstly, colleges and universities can set up insurance elective courses, so that students can understand the 
harmfulness of disease risk and enhance the awareness of disease risk management. Secondly, we should consciously popularize the relevant knowledge of students in daily school education, and guide students to form a correct view of medical treatment. Finally, colleges and universities should strengthen the health education of students, and actively carry out outdoor activities to promote the development of students' physical and mental health.

\subsection{Develop Health Management}

The development of college students' health management can be realized from two aspects, one is to establish college students' health examination system. Physical examination can help students find the potential disease as early as possible, and achieve the effect of early diagnosis and treatment. The second is to provide personalized health management services ${ }^{[5]}$. Through the information of personal health records, we can understand the existing health risk factors, and then provide comprehensive and targeted health security services for each student from the perspectives of society, psychology and biology.

\subsection{Improve Medical Service Ability}

First of all, university hospitals should perfect the internal management mechanism, correct the medical ethics, and provide excellent medical services according to the patient-centered service concept. Secondly, standardize the management of college students' health information and establish personal medical records for students. Finally, the university hospital should collect the feedback from the students on a regular basis, and correct the existing problems in a timely manner.

\subsection{Perfect Medical Security System}

Firstly, we should take into account fairness and efficiency, that is, the government should bear the main responsibility of the medical security system for college students, and try to open the intercollegiate medical service in the university city. Secondly, a multi-level medical security system for college students should be constructed $^{[6]}$, such as the establishment of special relief funds for major diseases and medical loans for college students, etc., from the economic point of view to ensure medical students to seek medical treatment in time after illness.

\section{References}

1. Wu Minmin, Mei Ren Lang. A study on the behavior of 1027 medical students in nine medical schools in the United States [J]. Foreign Medicine (Medical Education Volume),2001(01):9-13.

2. Yang Hui, Zhang Mimi, Ping Weiwei. Analysis of influencing factors of medical students' behavior of seeking medical treatment $[\mathrm{J}]$. Journal of Changzhi
Medical College, 2019, 33 (03): 173-176.

3. Wang Jun, Chang Zhongze, Liu Hong.A study on the behavior of health and medical needs of Chinese residents [J] .Economic Research, 2008 (7): 105-117.

4. Yu Dachuan, Li Yuqing. Medical treatment behavior of college students and its influencing factors: an empirical analysis based on microcosmic data [J]. Journal of Chongqing University of Commerce and Industry (Social Science Edition), 2016, 33 (02): 4248.

5. Cox D. Health service management-a sociological view: Griffiths and the non-negotiated order of the hospital[J]. The sociology of the health service, 1991: 89-114.

6. Zheng Chuan, Zhu Caihua, Peng Meihua, Li Yangqian. How to Improve the Medical Insurance System for College Students in China: Based on the Reference of International Experience [J]. Chinese Journal of Health Service Management, 2014, 31(06):437-438. 